\title{
Conserved and non-conserved enhancers direct tissue specific transcription in ancient germ layer specific developmental control genes
}

\author{
Sumantra Chatterjee ${ }^{1,2}$, Guillaume Bourque ${ }^{3}$ and Thomas Lufkin ${ }^{1,2^{*}}$
}

\begin{abstract}
Background: Identifying DNA sequences (enhancers) that direct the precise spatial and temporal expression of developmental control genes remains a significant challenge in the annotation of vertebrate genomes. Locating these sequences, which in many cases lie at a great distance from the transcription start site, has been a major obstacle in deciphering gene regulation. Coupling of comparative genomics with functional validation to locate such regulatory elements has been a successful method in locating many such regulatory elements. But most of these studies looked either at a single gene only or the whole genome without focusing on any particular process. The pressing need is to integrate the tools of comparative genomics with knowledge of developmental biology to validate enhancers for developmental transcription factors in greater detail

Results: Our results show that near four different genes ( $n k \times 3.2$, pax9, otx1b and foxa2) in zebrafish, only 20-30\% of highly conserved DNA sequences can act as developmental enhancers irrespective of the tissue the gene expresses in. We find that some genes also have multiple conserved enhancers expressing in the same tissue at the same or different time points in development. We also located non-conserved enhancers for two of the genes (pax9 and otx16). Our modified Bacterial artificial chromosome (BACs) studies for these 4 genes revealed that many of these enhancers work in a synergistic fashion, which cannot be captured by individual DNA constructs and are not conserved at the sequence level. Our detailed biochemical and transgenic analysis revealed Foxa1 binds to the otx 16 non-conserved enhancer to direct its activity in forebrain and otic vesicle of zebrafish at $24 \mathrm{hpf}$.

Conclusion: Our results clearly indicate that high level of functional conservation of genes is not necessarily associated with sequence conservation of its regulatory elements. Moreover certain non conserved DNA elements might have role in gene regulation. The need is to bring together multiple approaches to bear upon individual genes to decipher all its regulatory elements.
\end{abstract}

\section{Background}

One of the paradigms of development is the regulation of the genome in a precise and synchronized manner to form a highly complex embryo with diverse and specialized cell types. Though the major cell types in the embryo contain the same genetic material, they are very different from each other in both morphology as well as function. The generation of this cellular diversity by the genome is controlled by cis-regulatory elements. Cis-regulatory elements are DNA elements that are a key

\footnotetext{
* Correspondence: lufkin@gis.a-star.edu.sg

'Stem Cell and Developmental Biology, Genome Institute of Singapore, 60 Biopolis Street, 138672, Singapore

Full list of author information is available at the end of the article
}

component of the genome's non-coding functional sequences and consist of promoters, enhancers, silencers, insulators and locus control regions (LCR). The idea that animal development is regulated by cis-regulatory DNA elements is well established and has been elegantly described in invertebrates [1-3]. Of the many cisregulatory elements, enhancers are critical in modulating tissue specific and time dependent gene expression during embryonic development [4-7]. Enhancers are thought to consist of clustered target sites for a number of transcription factors and collectively form the genomic instructions for developmental gene regulatory networks. Hence any approach to elucidate such networks

\section{Biomed Central}


necessitates the discovery of all constituent enhancer elements and their genomic locations.

The identification and characterization of such cis-regulatory regions within the non-coding region of vertebrate genomes remains a challenge for the post genomics era. Traditionally enhancers have been identified through deletion assays $[8,9]$ and in vitro footprinting $[10,11]$. But recent advances in sequencing coupled with improved alignment tools have made comparative genomics one of the favored methods for enhancer detection [12-15].

It is suggested that $1 \%$ of the human non-coding genome is at least $70 \%$ conserved in the mouse genome over a region of $100 \mathrm{bp}$ or longer [16,17]. Many such conserved non-coding elements (CNEs) lie next to critical developmental control genes and have been shown to be developmental enhancers when selected and tested in mice and zebrafish $[14,18,19]$. It has also been demonstrated that genomic regions that have no sequence level conservation among different species can act as robust developmental enhancers $[13,20]$. Recently chromatin immunoprecipitation followed by massive sequencing (ChIP-Seq) for P300 and ChIP followed by microarray (ChIP-Chip) on histone modifying mark H3K4me3 (Histone 3 Lysine 4 trimethylation) has been shown to be useful in identifying tissue specific enhancers on a global scale, many of which have very weak sequence conservation [21-24]. Though such studies are a valuable resource they are limited by both the amount of material generated from a particular tissue as well as the availability of a specific antibody. It is also interesting to note that all enhancers are not marked by specific histone marks or co-activator proteins.

Our study takes a "gene centric" approach to locate and validate CNEs as transcriptional enhancers, thus helping to link an enhancer to gene expression and helping to understand transcriptional control of specific genes in greater depth. We looked for CNEs to validate as enhancers around four critical developmental control genes that are expressed in tissues that are ancient in origin and conserved in evolution. We sought to investigate if genes, irrespective of which germ layer they expressed in, followed the general trend of having both sequence conserved and non-conserved enhancers or if there was a bias depending on the germ layer. We picked one gene expressing in ectoderm $(o t x 1 b)$, one expressing in endoderm (foxa2) and two from mesoderm ( $n k \times 3.2$ and pax9). As mesoderm is considered to be of more recent origin [25,26], we chose 2 genes expressing in this particular germ layer to assess whether there was any bias in enhancer conservation due to evolutionary time. We hypothesized that using stringent conservation criteria over large phylogenetic distances will lead to a better filtering out of the functional enhancers from nonfunctional CNEs.

Using modified Bacterial artificial chromosomes (BACs) to detect regulatory elements is highly beneficial when testing for multiple regulatory domains from noncontiguous DNA, which act in concert to regulate expression of a gene $[27,28]$. It has also helped in cases where when the non-coding regulatory DNA is not conserved across species and thus not recognizable prior to testing. The success of this approach lies in fact that for genes with multiple expression domains, most of these domains can be observed in a single transgenic embryo as opposed to screening for multiple embryos for individual DNA constructs. Hence, we also modified the BACs containing the 4 genes of interest to locate and validate cis-regulatory elements, which are not conserved at the sequence level.

\section{Results}

nkx3.2

Bagpipe related homeobox containing genes are members of the ancient $N K$ gene family and are highly conserved in sequence and function from Drosophila to humans. In mammals it restricts the multipotential mesodermal progenitor to a chondroblast lineage and helps in the development and evolution of the axial skeleton in mouse and has potential role in human skeletal disorders [29-32]. It also has a known role in jaw joint formation and patterning [31,32]. $n k x 3.2$ has also been detected in the dorsal and anal fin radials of zebrafish as late as $10 \mathrm{dpf}$ and in the distal chondrocytes [33]. We detected $n k x 3.2$ expression by RNA in situ in the sclerotome and parts of anterior branchial arches at 24 and 48 hpf (Figure 1B, C).

\section{CNEs in and around $n k \times 3.2$}

UCSC genome browser's alignment of sequences near $N k \times 3.2$ in zebrafish revealed four conserved elements around the gene matching our criterion $(\geq 100 \mathrm{bp}$ length, $\geq 60 \%$ conservation) named $\mathrm{Bx} 1$ to $\mathrm{Bx} 4$ and varied in length from 318 to $990 \mathrm{bp}$ (Figure 1A and Additional File 1). These pieces were co-injected with the minimal promoter-EGFP construct into 1-cell zebrafish embryos and observed for EGFP expression in the domains of expression of $n k x 3.2$ in zebrafish at different time points. Only one DNA element, Bx4 drove EGFP expression that was detected along the antero-posterior axis in the region of the emerging sclerotome and myotome at $48 \mathrm{hpf}$ (Figure 1D and Additional File 2). Because transient transgenics in zebrafish tend to produce mosaic expression we did immunohistochemistry with an EGFP antibody to detect the exact expression domain of this enhancer as previously described [34]. Comparison with the RNA in situ data at the time point 

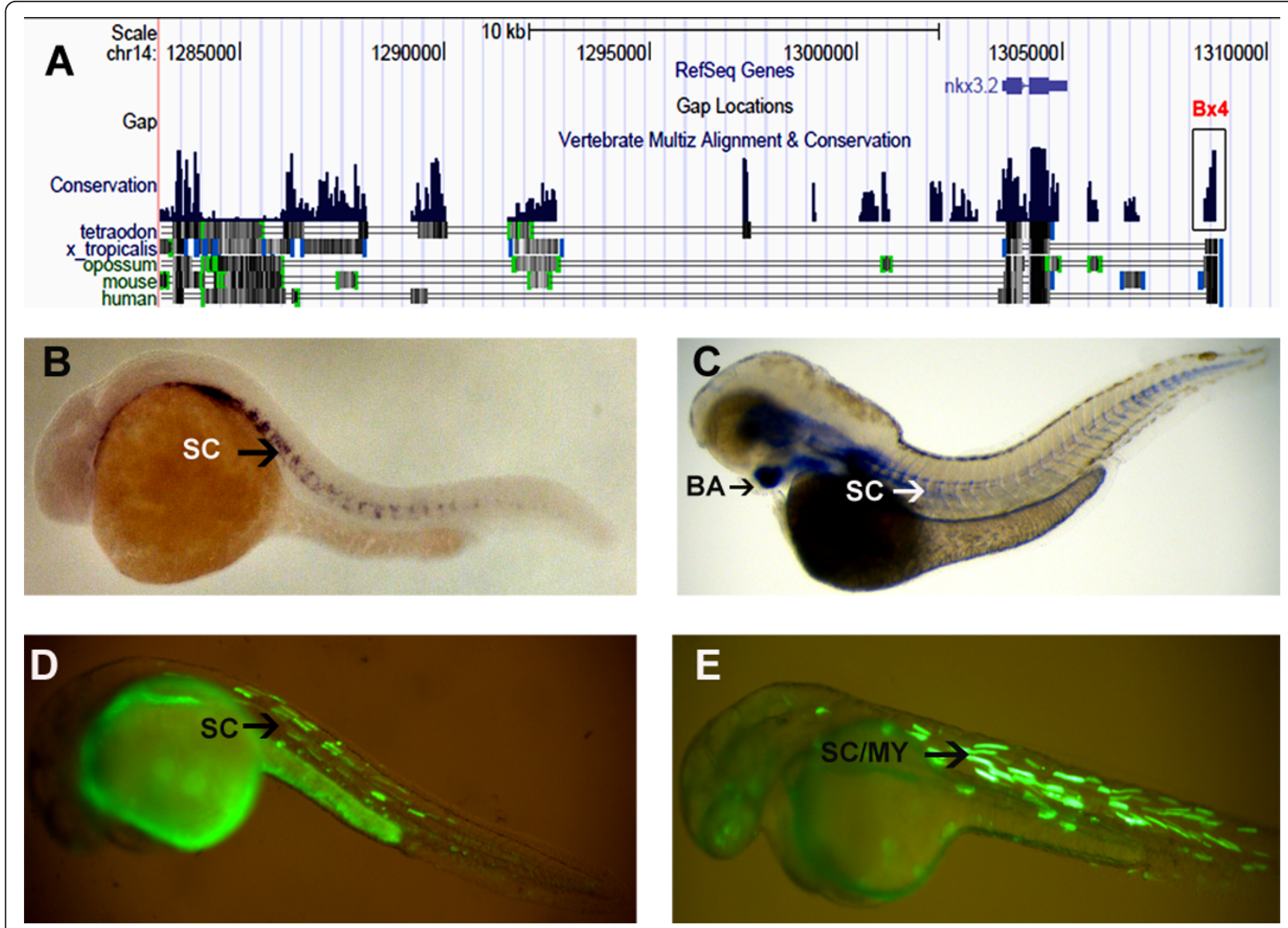

Figure $1 n k \times 3.2$ CNEs and modified BAC. (A) UCSC browser snapshot showing the synteny around $n k \times 3.2$ and the functional CNE Bx4. (B) Whole mount RNA in situ hybridization showing expression of $n k x 3.2$ in the sclerotome (SC) at $24 \mathrm{hpf}$. (C) Whole mount RNA in situ hybridization showing expression of $n k \times 3.2$ showing expression in branchial arch (BA) and sclerotome (SC) at 48 hpf. (D) Functional CNE Bx4 drives expression of EGFP in sclerotome (SC) at $24 \mathrm{hpf}$. (E) Modified BAC shows expression in both sclerotome and myotome (MY) at 24 hpf.

revealed the expression of the enhancer matched that of the endogenous gene (Additional File 3). There was no EGFP expression from the remaining CNEs at the developmental time points under observation. For this gene we also cloned all the four enhancer elements upstream of the promoter in the same order as they are found in the genome and this "mega" construct was also tested. We did not see any significant increase in expression level or domain from all the four enhancers versus only the single functional CNE (data not shown). Thus only 1 out of the 4 CNEs functioned as a developmental enhancer at all time points under observation.

\section{nkx3.2 BAC modification}

A $186 \mathrm{~kb}$ BAC (CH73-353E16) containing the zebrafish $n k x 3.2$ gene was identified from the UCSC genome browser and modified by inserting the EGFP ORF and a selection cassette was inserted just upstream of the translational start site of the gene (Additional File 4).
This ensured that the all the cis-regulatory elements in the $186 \mathrm{~kb}$ genomic region around $N k \times 3.2$ that was cloned into the BAC were captured in the assay. This modified BAC was injected into 1-cell zebrafish embryos and the embryos were followed over its development to detect EGFP in domains of expression of $n k x 3.2 .70 \%$ of the embryos gave distinct expression along the anteroposterior axis as marked by sclerotome/myotome, at 24 and $48 \mathrm{hpf}$ (Figure 1E), which correlated with the $n k x 3.2$ expression as detected by the RNA in situ (Figure 1C, D). We were however unable to detect any EGFP expression in the branchial arch, which is also a domain of expression for the gene. This led us to conclude that the regulatory elements for this domain lay outside the $186 \mathrm{~kb}$ genomic DNA present in the BAC.

$\operatorname{pax} 9$

pax9 is a member of the paired box $(P A X)$ family of transcription factors. Members of this gene family 
typically contain a paired box domain, an octapeptide, and a paired-type homeodomain. The paired domain consisting of 125-128 amino acids, encoded by the paired box, was named after the Drosophila pair-rule segmentation gene paired ( $p r d$ ) where it was first identified. There are nine known Pax genes in mouse (Pax1 to Pax9) and also humans (PAX1 to PAX9). Except Pax4 all other Pax genes also are present in zebrafish. In teleost fish there is evidence to suggest that $\operatorname{Pax} 9$ is indispensable for the development of the sclerotome and the neural arch [35]. Zebrafish pax9 expression is initiated at the end of the segmentation period in mesenchymal sclerotome cells on both sides of the notochord. Our RNA in situ hybridization detected expression of paxy in the dorsal sclerotome and parts of branchial arches at $36 \mathrm{hpf}$ (Figure 2B) and at $48 \mathrm{hpf}$ (Figure 2C)

\section{CNEs in and around pax9}

Alignment of the sequences around pax9 revealed 11 conserved elements matching our criteria ranging in size from $311 \mathrm{bp}$ to $1.2 \mathrm{~kb}$ (Figure 2A and Additional File 1) until there was a synteny break in one or both species that were used in the alignment. Six of these pieces were at the 5 ' end of the gene while five were from the 3 ' end, with the furthest being $178 \mathrm{~kb}$ away. Three out of these CNEs faithfully recaptured EGFP expression along the A-P axis as marked by the sclerotome/myotome when co-injected with the minimal promoterreporter construct. All the three CNEs drove expression of EGFP along the presumptive sclerotome and myotome at different time points in development. Elements Px2 and Px4 which were 23 and $27 \mathrm{~kb}$ away from the gene on the 5 ' end drove expression in the sclerotome and myotome at $36 \mathrm{hpf}$ (Figure 2D, E and Additional File 2), whereas Px7 which was $17 \mathrm{~kb}$ away from the gene at the 3' end drove EGFP expression in the same domain at $48 \mathrm{hpf}$ (Figure 2F and Additional File 2). Thus $27 \%$ of the CNEs around pax9 were functional in our assay for enhancers.

Since all the three functional CNEs were expressing in the cells along the antero-posterior axis which contain both the sclerotome and myotome, we did immunohistochemistry for EGFP as described previously on the

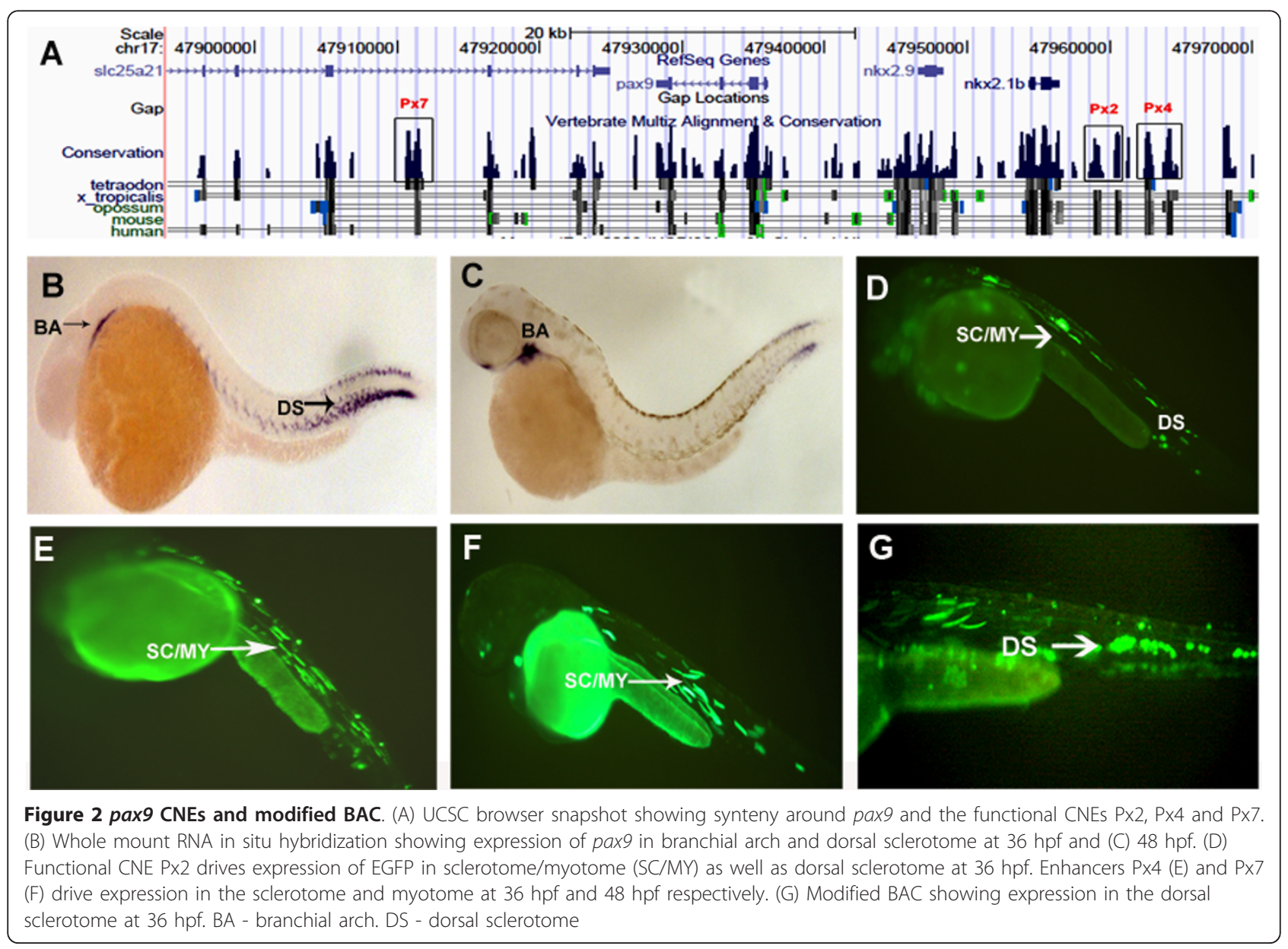


transgenic fish to ascertain the exact tissue which these enhancers were active in. Ours results show that all the three enhancers are expressing in the subset of sclerotomal cells which also expresses pax 9 as seen by RNA in situ hybridization. (Additional File 5)

\section{Branchial Arch enhancer of pax9}

Since pax9 expresses in the branchial arch and none of the CNEs around pax 9 could recapitulate the expression data, we decided to locate the enhancer by testing the whole 15 $\mathrm{kb}$ genomic region lying between the last exon of pax 9 and the functional enhancer Px7. We decided on testing the region on the 3'end of the pax9 gene, as the 5' end is gene rich containing $n k x 2.9$ and $n k x 2.1 b$ in close proximity. The 3' end only had one gene slc25a21, which had introns containing large stretches of non-coding DNA, and also contained one of the enhancer for pax9 (Px7). We did overlapping PCRs of about $500 \mathrm{bp}$ each to narrow down the enhancer to a 564 bp region (chr17:47,920,936$47,921,499$ ) (Figure 3A and Additional File 1) that could robustly drive activity in the branchial arch at $36 \mathrm{hpf}$. (Figure $3 \mathrm{~B}, \mathrm{C}$ ). This region does not show sequence conservation even with closely related fish species.

\section{pax9 BAC modification}

A $188 \mathrm{~kb}$ BAC (CH211-62I6) containing $188 \mathrm{~Kb}$ of genomic DNA flanking Pax9 was modified with EGFP and injected into 1-cell zebrafish embryo and followed over development. The modified BAC recapitulated the gene expression data in the sclerotome and myotome at 24 to 48 hpf. $70 \%$ of the embryos at $48 \mathrm{hpf}$ reproduced this expression pattern in dorsal sclerotome consistently (Figure $2 \mathrm{G}$ ).

\section{otx $1 b$}

Orthodenticle homolog 1 is a vertebrate homolog of the Drosophila orthodenticle and encodes a member of the bicoid sub-family of homeodomain containing transcription factors. Otx 1 along with $O t x 2$ has been implicated in the regional patterning of the rostral head and both are synergistic in function in certain domains of the brain. The $O t x 1$ gene has been strongly associated with the formation of the otic vesicle in gnathostomes starting with the teleost fish and hence helping in transition from the jawless vertebrates to a more gnathostome characteristics [36] and also in determining cerebellar cell identities in zebrafish [37]. Our RNA in situ hybridization detected expression of otx $1 b$ in neural plate at 6 hpf (Figure 4B) and forebrain, midbrain and otic vesicle at $48 \mathrm{hpf}$ (Figure $4 \mathrm{C}$ )

\section{CNEs in and around otx $1 b$}

Genome alignment revealed $16 \mathrm{CNEs}$ in the syntenic block around otx $1 b$ (Figure 4A and Additional File 1). All the CNEs were present on the 5' end of the gene
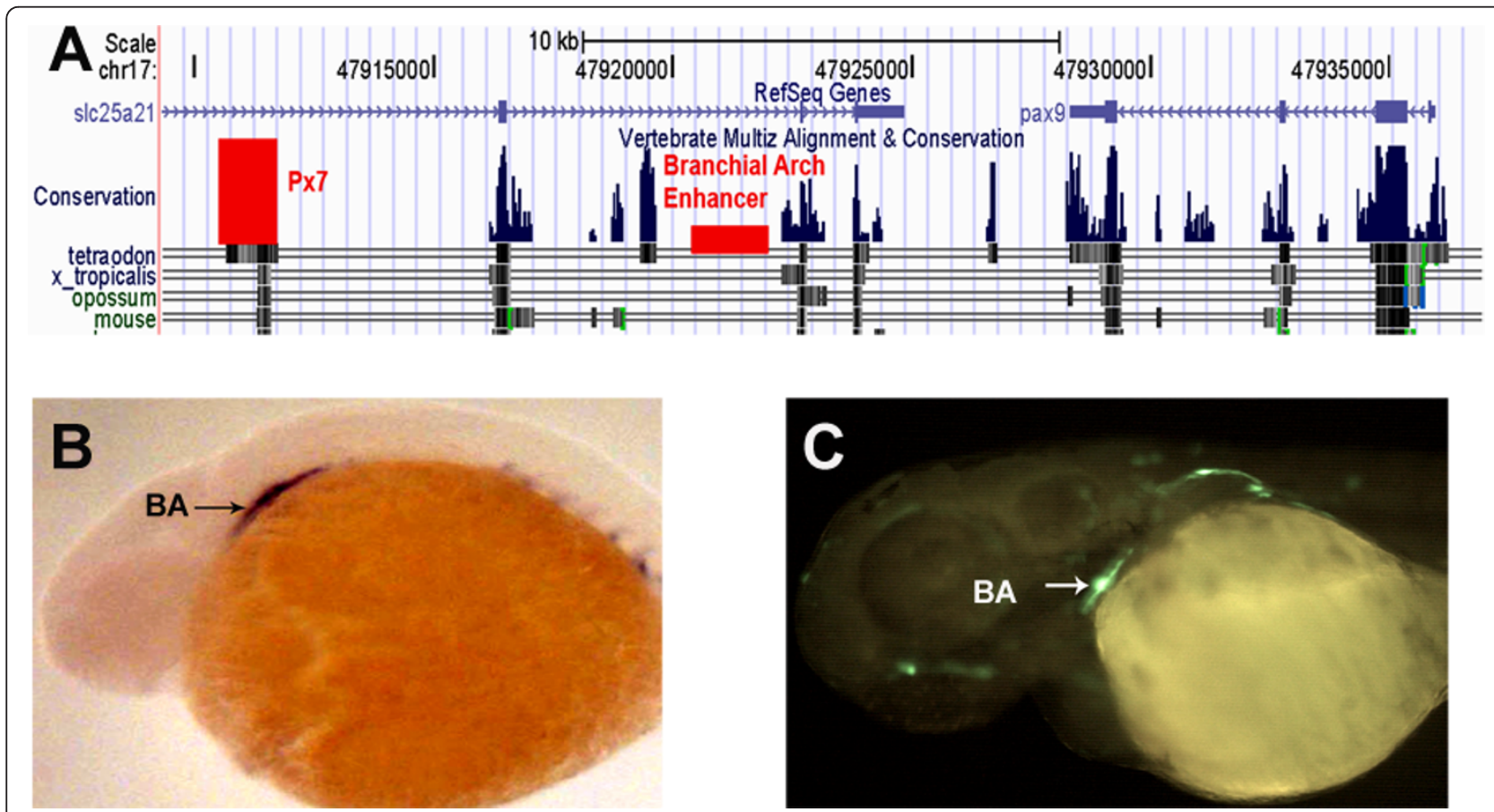

Figure 3 pax 9 non-conserved enhancer. (A) UCSC browser snapshot showing synteny around pax9 and the location of the functional CNE Px7 and the non conserved enhancer for branchial arch. (B) Whole mount RNA in situ hybridization showing expression of pax9 in branchial arch (BA) at 36 hpf. (C) A 500 bp non-conserved sequence drives expression of EGFP in the branchial arch at 36 hpf. 


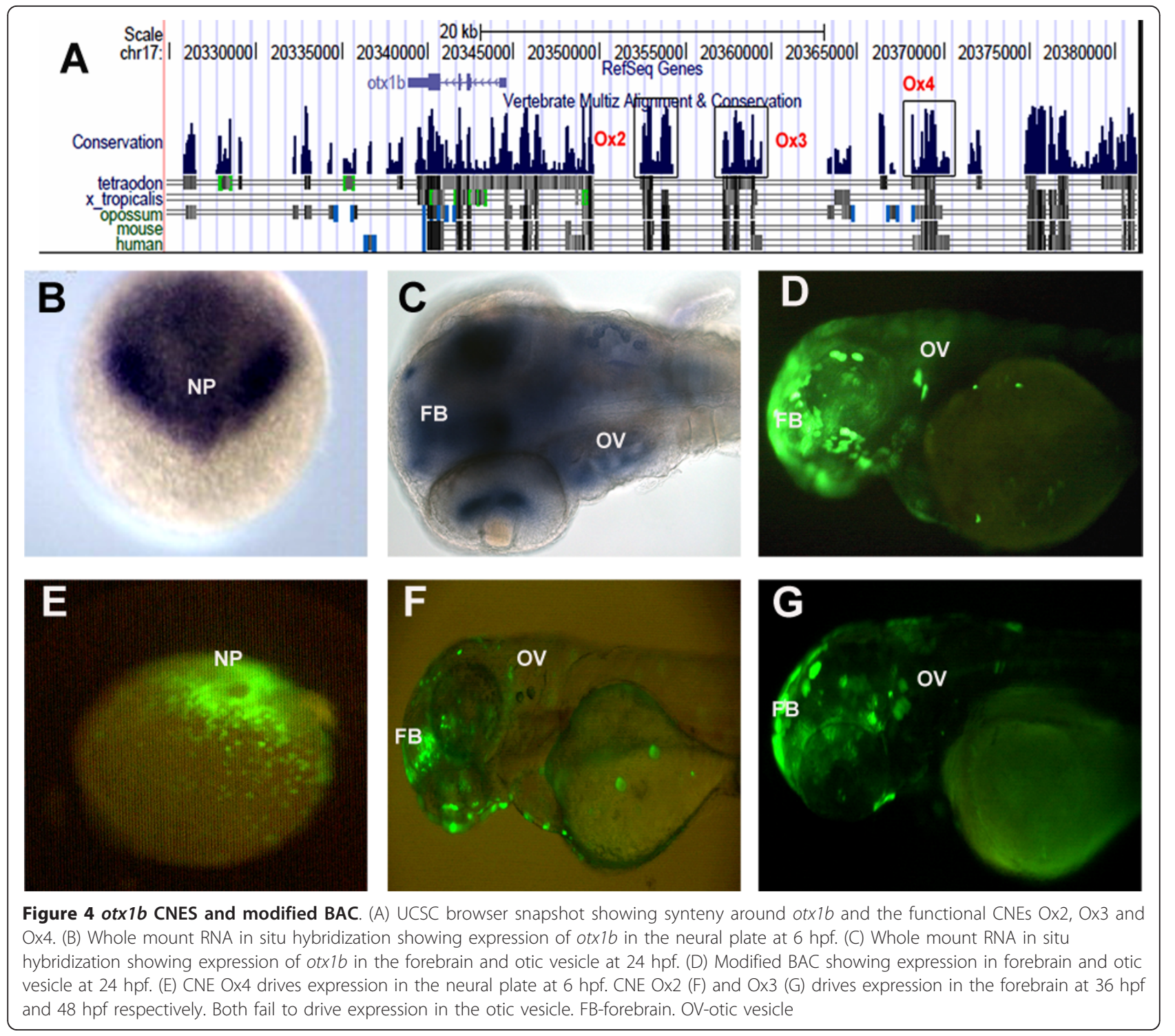

with the farthest being $172 \mathrm{~kb}$ away. There was no synteny at the 3' end of the gene with mouse and human genomes. Ox4 strongly recapitulated the gene expression at $6 \mathrm{hpf}$ at the neural plate (Figure 4E and Additional File 2). Both Ox2 and Ox3 that are adjacent to each other and about 8-10 kb away from the gene drove EGFP expression in the forebrain at $48 \mathrm{hpf}$ (Figure 4F, $G$ and Additional File 2). We did not detect any EGFP expression from the other CNEs when they were assayed individually with the reporter construct. Thus $19 \%$ of the conserved elements assayed in our system were positive as tissue specific enhancers.

\section{otx1b BAC modification}

The $111 \mathrm{~kb}$ BAC (CH73-220O18) containing the Otx1 gene was modified with a reporter and was injected into the 1-cell fertilized zebrafish embryos as previously described. The EGFP expression could be detected as early as $6 \mathrm{hpf}$ in the neural plate (data not shown). An individual CNE also drove reporter gene expression in the same tissue at the same time point and was present in the genomic region cloned in the BAC under testing. $69 \%$ of the injected embryos also showed EGFP expression in the forebrain midbrain and otic vesicle at $48 \mathrm{hpf}$, which overlapped with the endogenous gene expressions at the time point observed by RNA in situ (Figure 4D). We detected a much more extensive expression domain for the BAC as compared to the individual CNEs, thus leading us to believe that there exist more regulatory elements in that genomic region than detected by sequence level constrain. 


\section{foxa2}

foxa 2 is a member of the forkhead transcription factor family and is specifically expressed in the visceral endoderm, anterior definitive endoderm, node, notochord and floorplate [38-40]. In zebrafish it has been shown that although foxa 2 is not required for the induction of the floorplate, it is required for its further differentiation and for induction and/or patterning of several distinct cell types in the ventral CNS [41]. Our RNA in situ hybridization detected expression of foxa 2 along the forebrain and the pharyngeal endoderm at $48 \mathrm{hpf}$ (Figure 5B-D).

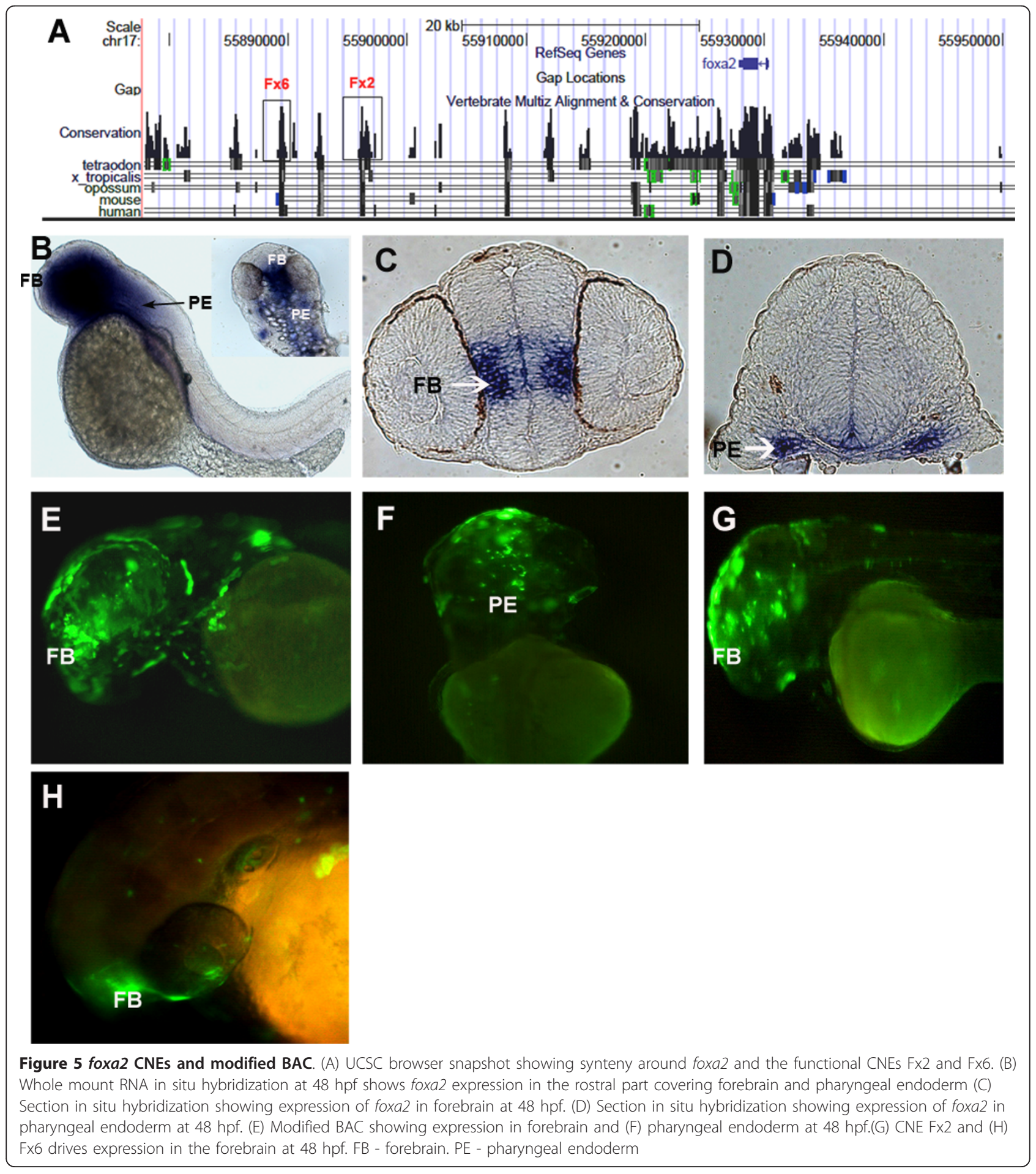




\section{CNEs in and around foxa2}

Using our criteria, we located six CNEs around Foxa2, all of which were located at the 3' end of the gene, the closest being $2 \mathrm{~kb}$ away and the farthest being $60 \mathrm{~kb}$ away and ranging in size from $425 \mathrm{bp}$ to $1220 \mathrm{bp}$ (Figure 5A and Additional File 1). Each of these CNEs was individually ligated with the reporter construct and the injected embryos were visualized at different time points in development. Two of the CNEs, Fx2 and Fx6 could drive expression in the forebrain at $48 \mathrm{hpf}$ (Figure 5G, $\mathrm{H}$ and Additional File 2). There was no detectable expression of EGFP from the other individual CNEs at the time points under observation. So only $33 \%$ of the CNEs assayed were functional as developmental enhancers in zebrafish.

\section{foxa2 BAC modification}

The $179 \mathrm{~kb}$ BAC (CH211-38M14) containing the genomic insert in and around zebrafish foxa 2 was modified and injected into 1-cell zebrafish embryos. The BAC recapitulated the endogenous gene expression particularly in the rostral end of the embryo in the forebrain and pharyngeal endoderm at $48 \mathrm{hpf}$ (Figure 5E-F). We failed to detect EGFP expression in any other foxa 2 expression domains.

\section{Bac dissection to detect non-conserved enhancers}

Since many of the CNEs failed to act as enhancers coupled with the fact that our data on $\operatorname{pax} 9$ as well as previous studies reported the presence of non-conserved enhancers [20] we sought to investigate in a detailed manner if we could locate more such functional nonconserved enhancers. Since most of our modified BACs gave us expressions that were more extensive than the individual CNEs alone, we employed the traditional method of BAC dissection. We selected the otx $1 b$ BAC for these experiments as the modified BAC for this gene had shown a robust spatio-temporal expression, recapitulating substantial domains of expression of the endogenous gene (Figure 6E). The BAC was digested with the restriction enzyme XbaI, which generated 22 fragments ranging from $48 \mathrm{bp}$ to $27 \mathrm{~kb}$ in size (Figure 6A). The fragments were individually ligated to the minimal reporter construct and injected into 1-cell zebrafish embryo. Three fragments gave EGFP expression in the fore and/or mid brain of the zebrafish embryo at 24 and 48 hours. Two of the positive fragments each contained a functional CNE in them (Ox2 and Ox3). The third fragment, a $6.4 \mathrm{~kb}$ piece from the $3^{\prime}$ end (chr17:20,307,773-20,314,262) of zebrafish Otx1b gene mapped to a large region that included introns and exons of a predicted gene (Ensembl Transcript: ENSDART00000090374). Also this fragment was conserved in among the fishes-Fugu and Tetraodon. This element was functional in our assay expressing in forebrain and otic vesicle (Figure 6F). The fact that it mapped to such a large region that included exons led us to believe that the core element might be smaller. This $6.4 \mathrm{~kb}(\mathrm{NC})$ regulatory element was further reduced into five overlapping $1050 \mathrm{bp}$ and one $1500 \mathrm{bp}$ fragment by PCR (Figure 6B). The overlapping PCR fragments ensured we did not have abrupt breakpoints in the DNA fragments. These six fragments (NC1-NC6) were individually tested by co-injection with the minimal reporter construct into zebrafish embryos and one (NC2) of the 1050 bp fragments (chr17:20,312,333$20,313,342$ ) partially recapitulated the expression domain of the bigger $6.4 \mathrm{~kb}$ fragment at 24 and $48 \mathrm{hpf}$ (Figure 6G). There was no expression from the other 5 fragments. NC2 showed partial conservation to the tetraodon and fugu genome. $\mathrm{NC} 2$ was further reduced to five (NC2A-NC2E) 210 bp fragments by doing overlapping PCRs and each piece was individually injected with a reporter construct (Figure 6C). Fragment NC2C (chr17:20,312,743-20,312,952) on its own could drive expression of EGFP reporter in a subset of the expression domain of NC2 (Figure 6H), which was a subset of the expression domain of the $6.4 \mathrm{~kb}$ fragment in the forebrain and otic vesicle. Interestingly the NC2C 210 bp fragment had no conservation with any species in the genome alignment. Thus we concluded that this element was a zebrafish specific enhancer for $o t x 1 b$. We also observed that reducing the size of the DNA resulted in a slight reduction both in the domain of expression as well as the level of expression in the embryo. One possible reason for this reduction in expression domain was that, although the small $210 \mathrm{bp}$ fragment contained most of the transcription factor binding sites essential for its function, it was missing some other binding sites which were in the neighboring fragments and the extensive expression domain as seen by the $6.4 \mathrm{~kb}$ fragment is result of the synergistic activity of multiple transcription factors interacting with the regulatory element.

\section{Biochemical and transgenic assays to detect a core binding site}

Seven overlapping Cy5 labeled DNA probes were designed to span the 210 bp Otx $1 b$ non-conserved enhancer (NC2C) (Figure 6D). The probes were incubated with nuclear extract from $24 \mathrm{hpf}$ zebrafish embryos and run on a native gel (EMSAs). Two out of the seven fragments showed a distinct shift indicating that they contained sites for transcription factor binding (Figure 7A). Both of these fragments were co-injected with the EGFP reporter construct into 1-cell zebrafish embryos. One of the fragments (EM4) could drive EGFP expression to the rostral portion of the brain, 


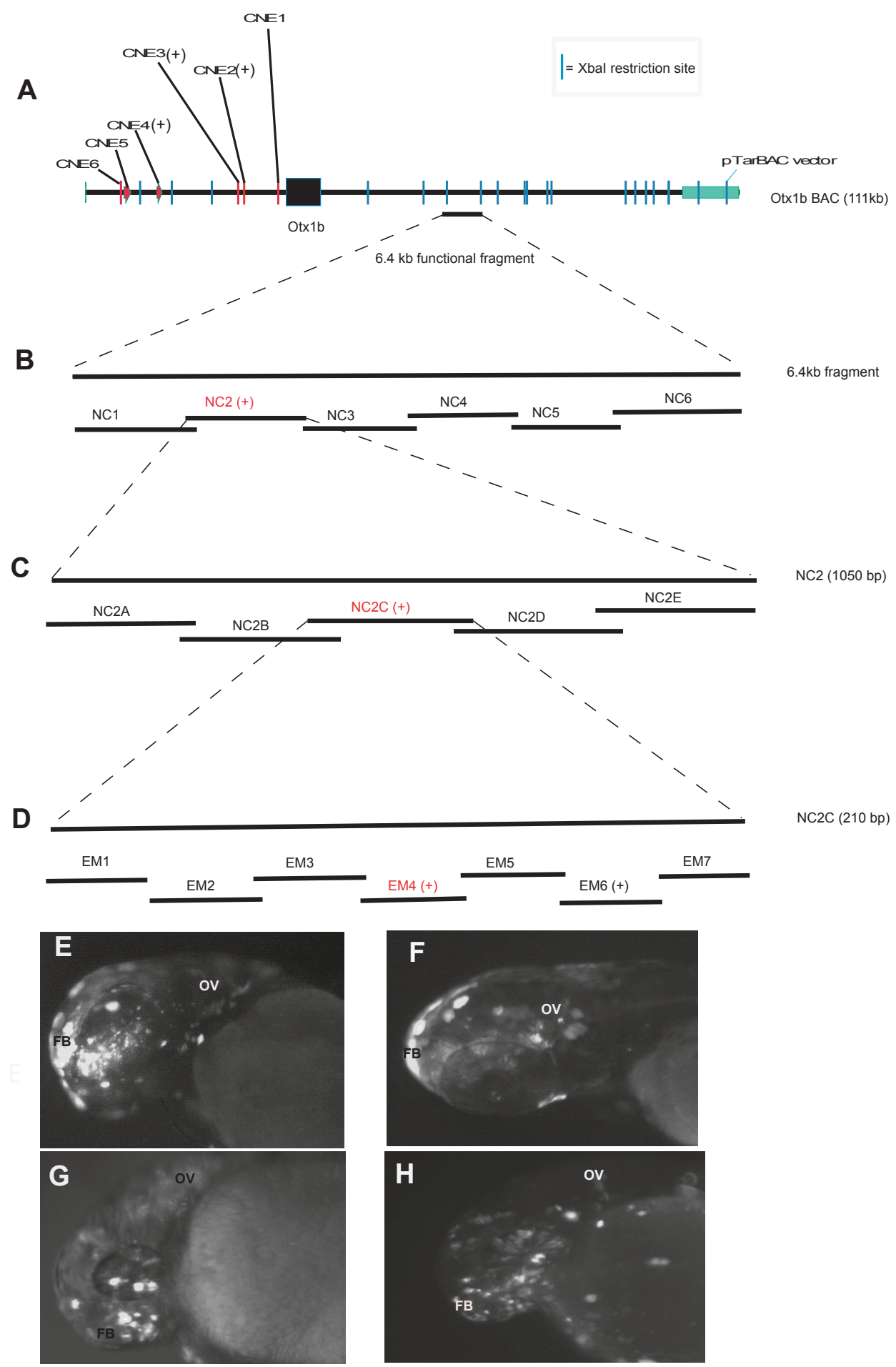

Figure 6 BAC dissection to detect otx1b non-conserved enhancer. (A) The Otx1b $111 \mathrm{~kb}$ BAC showing the gene and the $6.4 \mathrm{~kb}$ nonconserved functional element and the CNEs present. The blue lines indicate the Xbal restriction sites. The plus sign in parenthesis indicates functional CNEs. (B) Six overlapping PCR fragments covering the 6.4 kb fragment. (C) Five overlapping PCR fragments covering the 1050 NC2 functional fragment (D) the seven Cy5 labeled probes designed on the functional NC2C fragment. Transgenic assay with the whole BAC (E), 6.4 kb fragment (F), NC2 (1050 bp) fragment (G) and NC2C (210 bp) fragment (H) all at $24 \mathrm{hpf}$. 


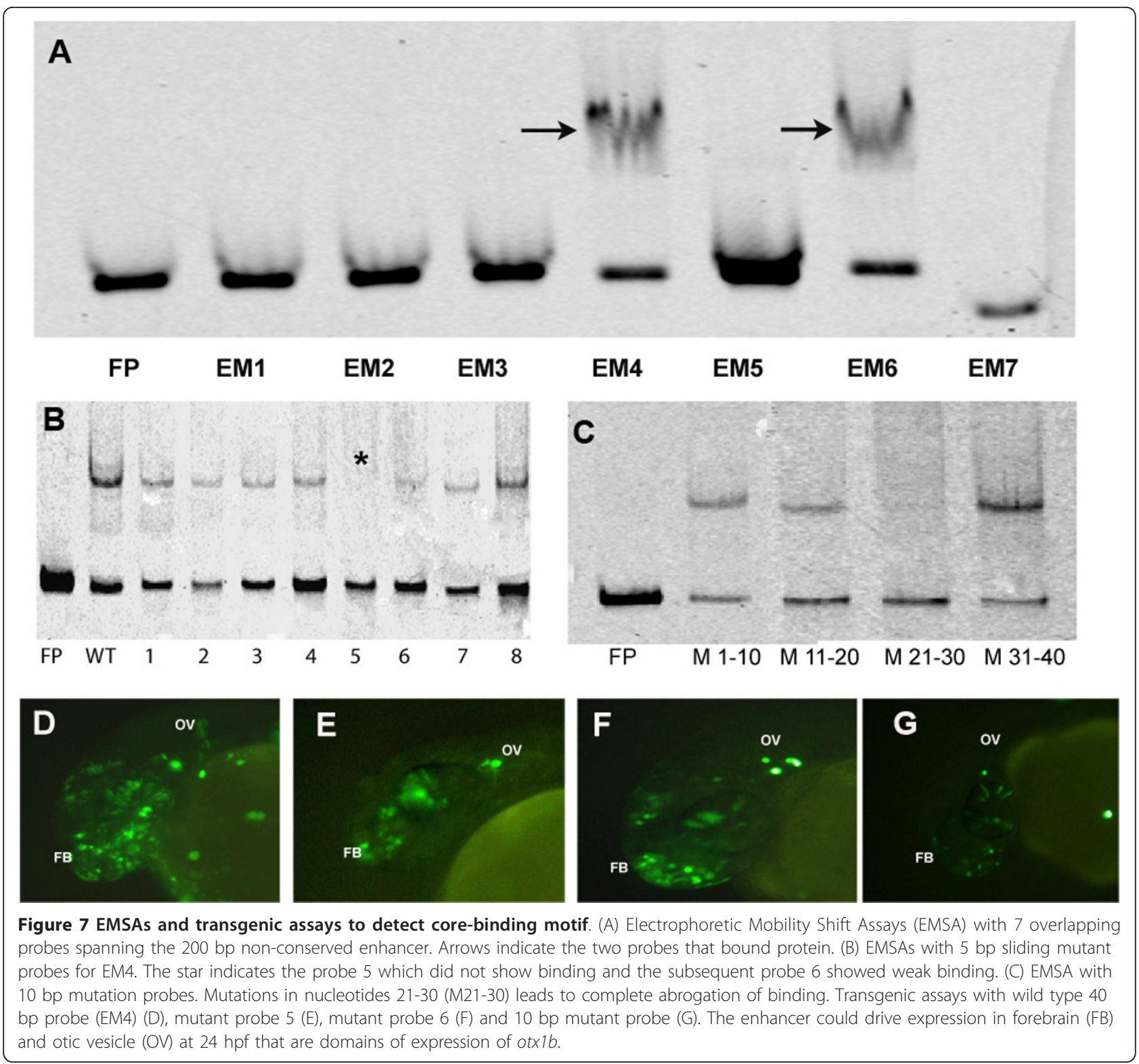

recapitulating a subset of the expression domain of the bigger 200 bp fragment (Figure 7D). The other fragment (EM6) that bound protein in vitro did not show any activity in vivo.

We made "sliding" 5 bp mutations (nucleotide transversions e.g. A to $\mathrm{C}$ ) along the $40 \mathrm{bp}$ (EM4) region to narrow down the binding site (Additional File 6). Mutations in nucleotide 21 to 25 (GGAGG) completely abrogated binding of the protein with weakened binding observed for mutations in nucleotides 26-30(GAGGG) (Figure 7B). Injection of the EGFP reporter construct harboring the mutant $5 \mathrm{bp}$ binding sites independently in the zebrafish showed weakened EGFP expression but not complete loss of activity (Figure 7E, F). This led us to believe that the nucleotide 21-30 together harbored the functional site in the enhancer. We went ahead and designed mutant probes for the whole $10 \mathrm{bp}$ (21-30 nucleotides) region and EMSA and transgenic assays showed a complete abrogation of binding and markedly reduced EGFP expression in the zebrafish embryos (Figure $7 \mathrm{C}, \mathrm{G})$. This gave conclusive proof that the actual binding site and the core functional domain of the nonconserved enhancer lay within these 10 nucleotides.

\section{Enhancer binding transcription factor}

We used the TRANSFAC database (http://www.generegulation.com/index.html) [42] to find potential transcription factors (TFs) that could bind to the $10 \mathrm{bp}$ 
sequence in our non-conserved enhancer. By using a criterion of entire matrix similarity $>0.75$ we came up with a list of 3 putative transcription factors that could bind the sequence: Foxa1, Pbx2, and Lef1 (Additional File 6). We performed supershift assays with antibodies against the potential TFs and saw a supershift uniquely with the Foxa1 antibody (Figure 8A). To conclusively prove that Foxa1 was critical for the functioning of the enhancer we designed 2 morpholinos against Foxa1 and co-injected the morpholinos with the 40 bp non-conserved enhancer construct. Whereas the scrambled morpholino (Figure 8C) did not have any effect on the enhancer and recapitulated the expression of the enhancer alone (Figure 8B), knocking down Foxa1 resulted in a dramatic reduction of the enhancer activity by both the morpholinos (Figure 8D, E). To verify if Foxa1 was

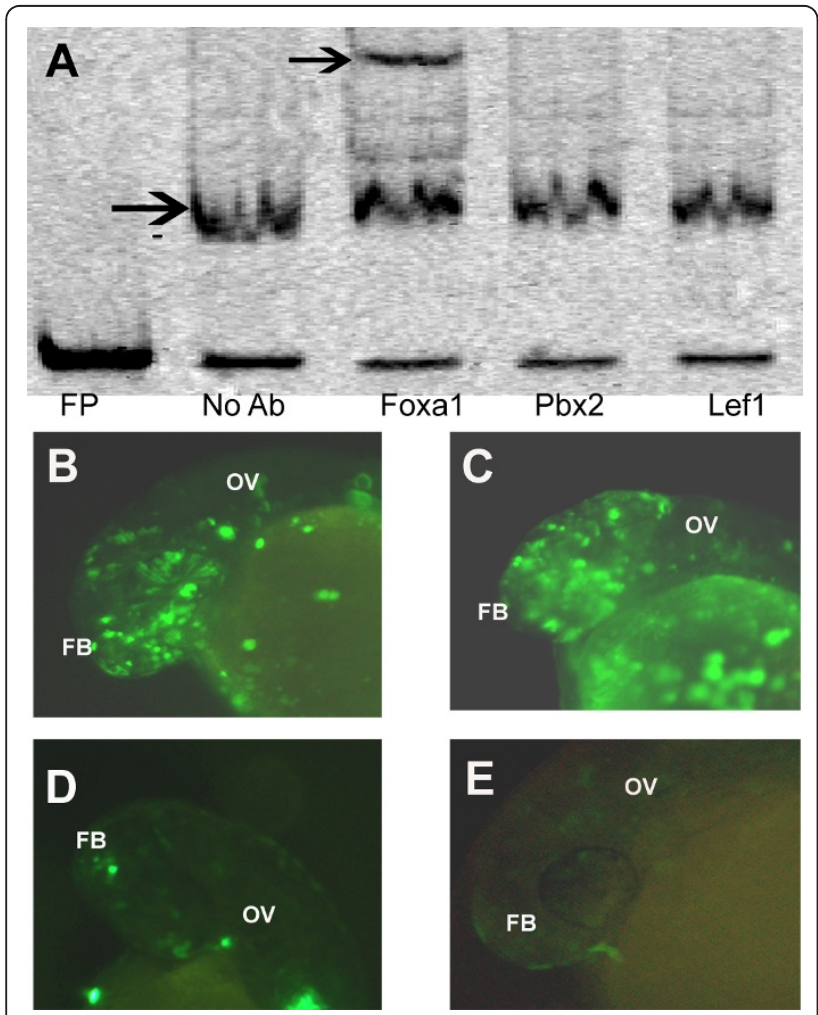

Figure 8 Elucidation of transcription factor binding to the enhancer. (A) Supershift assay with Foxa1, Pbx2 and Lef1 antibodies. Black arrow in no Ab lane denotes the shift and the one in Foxa1 added lane denotes supershift. (B) Expression of the $40 \mathrm{bp}$ sequence (EM4) driven EGFP construct in forebrain (FB) and otic vesicle (OV) which are domains of expression of otx 16 at $24 \mathrm{hpf}$. (C) Co-injection of the $40 \mathrm{bp}$ enhancer along with a scrambled morpholino, showing no down regulation of the enhancer activity at $24 \mathrm{hpf}$. (D) Co-injection of the $40 \mathrm{bp}$ enhancer along with morpholino 1 (M1) against Foxal showing reduction in the enhancer activity at $24 \mathrm{hpf}$. (E) Co-injection of the $40 \mathrm{bp}$ enhancer along with morpholino 2 (M2) against Foxal showing reduction in the enhancer activity at $24 \mathrm{hpf}$. indeed knocked down in the morphants, we did western blots, as previously described [34], to detect proteins levels of Foxa1. The western blots indicated that both the morpholinos used against Foxa1 resulted in dramatic decrease in levels of Foxa1, which were not seen in the scrambled morpholino control (Additional File 7 Figure A). To test if downregulation of Foxa1 and decreased activity of the $o t x 1 b$ enhancer actually led to a dramatic drop in expression of otx $1 b$ we did RT-PCR on RNA extracted from both wild type as well as morphant embryos at $24 \mathrm{hpf}$ (Additional File 7 Figure B) as well as RNA in situ for $o t x 1 b$ in both these embryos (Additional File 7 Figure $\mathrm{C}$ ). There was no discernable expression change detected by PCR or in situ, strongly suggesting that the expression of $o t x 1 b$ at $24 \mathrm{hpf}$ is also controlled by other functional enhancers thus the abrogation of activity of one regulatory element does not lead to significant drop in its expression. Hence our data suggests that Foxa1 is important in driving the activity of otx $1 b$ in the forebrain and otic vesicle in zebrafish via a redundant enhancer which is not conserved at the sequence level.

\section{Discussion}

This study focused on examining CNEs directing expression of four developmental control genes that are ancient in origin and conserved during evolution and expressed in the three different germ layers. This allowed us to ask two very important questions regarding the nature and role of these conserved elements: (1) are all the conserved elements found in the syntenic region around a gene functional? (2) Can we find all the enhancers for a particular gene by looking only at the CNEs? The CNEs selected for our study were selected based on a criteria of $\geq 60 \%$ sequence identity and $\geq$ $100 \mathrm{bp}$ in length across three phylogenetically distant species (human, mouse, zebrafish). As the teleost fishes and mammals last shared a common ancestor about 450 million years ago, predating the emergence of the majority of all extant vertebrates, it strongly implied that any non-coding sequences conserved between these two groups are likely to be fundamental to vertebrate life and hence functional. The design of our study has also allowed us to address some major arguments which have been put forward before to explain the absence of functionality in these CNEs in human-mouse comparative studies. By being able to look at potentially all developmental time points we had an advantage over most of the studies where the functional testing was done in mouse and was restricted to one developmental time point [14]. Yet our data clearly indicates that even DNA elements that are conserved very stringently over long evolutionary time might not have functional roles as enhancers during development. The fact that many of 
these conserved non-coding elements are non-functional as enhancers and non-conserved DNA can be functional is not totally unexpected. Previous studies $[9,20]$ by other groups looking at single genes also revealed similar trends in other genomic loci in the zebrafish. Conversely it has also been shown that absence of sequence level homology does not preclude a fragment of DNA from being functional as a developmental enhancer $[13,43]$. Thus our data supports the hypothesis that in zebrafish many of the enhancers for important developmental control genes are not constrained at the sequence level.

We have also demonstrated that there is still a need to combine high throughput comparative genomics with detailed biochemical assays to locate and validate cisregulatory elements in the vertebrate genome. By doing such detailed assays on one of the non-conserved enhancers we have demonstrated that putative transcription factor binding sites and the actual transcription factor binding to an enhancer can be determined with great accuracy and can lead to a more complete analysis of an enhancer. Though a recent study discovered motifs in zebrafish enhancers, they only predicted what putative transcription factors could bind them [44], we went beyond only prediction and actually validated the responsible transcription factor. We believe our study will help in opening the door for future studies looking in finer detail at individual enhancers and how they control gene expression.

We have also shown the utility and efficiency of using BAC transgenics in zebrafish to locate and validate distal cis-regulatory elements for different genes. BACs have been successfully used to validate cis-regulatory elements for numerous genes in mouse $[28,45]$ and in certain cases multiple overlapping BACs have been used to locate all the regulatory elements of a gene [27]. BAC modification for transgenics has also been employed for a few zebrafish genes in the past [46-49]. We have done an extensive spatio-temporal gene expression study of BAC transgenics for four critical developmental control genes. Thus we have demonstrated that circular modified BACs can be used without linearization for largescale transgenic studies in zebrafish making it an attractive model system for similar future studies.

Finally it has not escaped our attention that only about $20-30 \%$ of the CNEs tested were functional as developmental enhancers. Most of these fragments could indeed be non-functional but alternately other possible explanations exist. One possibility is that these elements are acting in a synergistic manner and require other elements together to function. This was also demonstrated by our BAC studies, which show much more extensive expression patterns as compared to the individual CNEs. Also the possibility exists that these
CNEs could be negative regulatory elements and hence our assay fails to capture this activity. Some recent results from other groups have indicated the same for the human genome [15]. Also other functions such as chromatin attachment sites, miRNA genes or splice regulatory regions may also reside in such highly conserved non-coding sequences [50-54].

\section{Conclusions}

Thus it is becoming increasing clear that the degree of sequence conservation is not a measure of how 'important' or 'crucial' a functional element might be, but its relevance is shaped by the underlying molecular mechanisms that determine its particular function. Hence as we demonstrated here, future needs will be to combine evolutionary, functional and bioinformatic approaches to understand how these sequences function at the molecular level to determine the nature of these interactions and finally decipher what $98 \%$ of our genome encodes.

\section{Methods}

\section{RNA in situ hybridization}

DNA clones for making in situ hybridization probes were obtained from the Expressed Sequence Tag (EST) clone collection at the Genome Institute of Singapore and whole mount in situ hybridization using digoxigenin (Roche) labeled RNA probes was performed as described previously [55]

\section{Fish maintenance and embryo staging}

Fish were maintained in the GIS zebrafish facility according to standard procedures. Crosses were set up in the evening and the barrier was lifted the next morning. After half an hour, the fertilized embryos were collected and maintained at $28.5^{\circ} \mathrm{C}$ in egg water supplemented with methylene blue. The stages of embryos were indicated as hpf (hours post-fertilization) or dpf (days post-fertilization) [56]. From 24 hours onward the embryos were raised in egg water containing Phenylthiourea. This helps to prevent pigmentation and allows better visualization of the Enhanced Green Fluorescent Protein (EGFP) signal. The GFP2 filter of stereomicroscope (Leica Microsystems, Germany) was used to observe the EGFP signals in transgenic zebrafish. The Leica DFC camera was used to take photographs and was captured using the IM50 software from Leica.

\section{Genome alignments and Conserved Non-coding Elements (CNEs)}

The University of California Santa Cruz (UCSC) genome browser's (http://genome.ucsc.edu) zebrafish (Danio rerio) Zv6 genome assembly was used as a base genome to align the genome sequences with mouse $(\mathrm{mm} 8$ 
assembly) and human (hg18 assembly) for regions around genes of interest. This assembly was used initially as the comparative genomics tracks were best annotated. Aligning the sequences with a recent assembly (Zv8) has shown that all the CNEs tested have still remained conserved and non-coding in the new annotation. For the positive CNEs the new coordinates from the Zv8 assembly are listed in Additional File 1. The closest gene to the start of each CNE was determined by the looking at known gene annotations on the UCSC genome browser. The UCSC browser's conservation tracks (phastcon conserved elements) were used to determine conserved elements ( $\geq 60 \%$ identity, $\geq 100 \mathrm{bp}$ length). Transcribed sequences in the conserved set were filtered out using known genes, spliced ESTs and mRNA annotations (intronic conservation was allowed). We confined our search for CNEs up to $1 \mathrm{Mb}$ or till wherever there was a break in synteny around the gene of interest between the three species (zebrafish-mousehuman).

\section{Functional Assays}

We assayed for enhancer activity in embryos by either co-injecting the candidate enhancer element with a minimal promoter-reporter vector in a method previously described $[19,57]$ or by ligating individual CNEs to the minimal vector. Though there has been suggestions that using transposon based vectors might be a more efficient way to assay for enhancers, our previous study and also studies from other labs have shown that circular vectors containing the enhancer-reporter construct as well as co-injection of the reporter construct with the DNA are equally efficient in transient transgenic assays in zebrafish [34,58]. In a series of control experiments we injected just the reporter construct alone (negative control), which was found to be transcriptionally inactive on its own. For preparation of DNA for microinjections, CNEs were PCR amplified from zebrafish genomic DNA or bacterial artificial chromosomes (BACs) containing the region of interest (50100 bp sequences immediately flanking the core conserved region on either side was included in the PCR). DNA was purified using the QIAquick PCR purification kit (Qiagen, USA). The minimal vector was constructed by cloning in the EGFP ORF (Clontech, USA) under the control of a minimal promoter from the mouse $\beta$-globin gene. This fragment was released from the vector backbone using SmaI restriction enzyme and gel purified using QIAquick gel extraction kit (Qiagen, USA). Element DNA (at $20-50 \mathrm{pg} / \mu \mathrm{l})$, reporter fragment $(50 \mathrm{pg} /$ $\mu \mathrm{l})$ and phenol red $(0.1 \%$ as tracer) were combined and injected into at least 2001 -cell zebrafish embryos using a Pico-Injector (PLI-100 Harvard Instrument, USA).
Three independent injections were done for all constructs (Additional File 2).

For locating the $\operatorname{pax} 9$ non-conserved branchial arch enhancer, we did 500 bp overlapping PCRs spanning the $15 \mathrm{~kb}$ genomic region (chr17:47,911,703-47,927,438) from the final exon of pax9 to the functional CNE Px7 which is located in the third intron of the neighboring gene $s l c 25 a 21$. Each fragment was ligated to the reporter construct individually tested. We did not PCR out the three exons of the slc25a21. The embryos were observed at various time points in development (from $6 \mathrm{hpf}$ to 3 dfp) for GFP expression. On basis of the GFP expression a CNE was scored as 1) positive, 2) negative or 3) positive but not in "expected" domain of the gene. The domains of expression were annotated by referring to the RNA in situ hybridization results for the gene and also by cross-referring to existing gene expression data at ZFIN (The Zebrafish Model Organism Database) (http://www.zfin.org).

\section{BAC targeting construct and modification}

The UCSC genome browser was used to locate 150-250 $\mathrm{kb}$ BACs containing the gene of interest. A BAC was selected which contained sufficient flanking genomic sequences around the gene. This enabled us to retain the regulatory elements in their proper genomic context and hence increase the possibility of capturing the maximum number of distal cis-regulatory elements. A BAC targeting vector was constructed by PCR amplifying a FRT-PGK-gb2-NEO-FRT cassette from a commercially available vector (Gene Bridges, $\mathrm{GmbH}$ ). This was cloned into the NotI site of a pBlueScript vector SK+ (Stratagene, USA) containing the EGFP ORF between its XhoINotI sites. This fragment containing the EGFP ORF and selection cassette was PCR amplified with 50 bp homology arms on either side of the translational start site of each gene of interest and homologously recombined using the GeneBridges BAC modification kit (Gene Bridges, $\mathrm{GmbH}$ ) as per the manufacturer's instructions (Additional File 4) [59]. Circular modified BAC DNA was purified using Qiagen Maxiprep kit and injected into one-cell zebrafish embryo and EGFP expression followed over development.

\section{BAC dissection}

The otx $1 b$ BAC was digested with XbaI restriction enzyme and the fragments generated were co-injected with the reporter vector into embryos. The fragments that drove EGFP expression were mapped back to the zebrafish genome assembly to determine its position with respect to the $o t x 1 b$ gene. The $6.4 \mathrm{~kb}$ non-conserved fragment was further subdivided into $1 \mathrm{~kb}$ and 200 bp fragments by generating overlapping PCRs. The 
$200 \mathrm{bp}$ PCR generated genomic fragment that drove expression of EGFP was used in subsequent EMSAs.

\section{Electrophoretic mobility shift assays (EMSAs)}

Nuclear proteins were extracted from 24 hpf zebrafish embryos using the NE-PER nuclear and cytoplasmic extraction kit (Thermo Scientific, USA). EMSAs were carried out using DNA probes modified with 5' Cy5 labels (Sigma Proligo). The 200 bp non-conserved functional element was sub divided into six $40 \mathrm{bp}$ and one $30 \mathrm{bp}$ overlapping fragments having a $10 \mathrm{bp}$ overlap. Equimolar amounts of complementary strands were mixed and heated to $95^{\circ} \mathrm{C}$ followed by gradual cooling to ambient temperature over at least $5 \mathrm{~h}$ to anneal the probes. For binding studies, double-stranded DNA probes at $10 \mathrm{nM}$ were mixed with 10 ug of nuclear proteins and 500 ng of Poly dI-dC (Sigma) in a buffer containing $40 \mathrm{mM}$ Tris- $\mathrm{HCl}(\mathrm{pH} 8.0), 0.4 \mathrm{mg} / \mathrm{ml} \mathrm{BSA}, 200$ $\mathrm{uM} \mathrm{ZnCl}_{2}, 400 \mathrm{mM} \mathrm{KCl}, 40 \%$ glycerol and $0.4 \%$ IGEPAL and incubated at $4{ }^{\circ} \mathrm{C}$ in the dark for one hour. The bound and unbound probes were subsequently run on a pre-run $8 \% 1 \mathrm{X}$ TBE polyacrylamide gel for approximately $30 \mathrm{~min}$ at $200 \mathrm{~V}$. The fluorescence was detected using a Typhoon 9140 PhosphorImager (Amersham Biosciences). At least three independent experiments for each binding site were performed to ascertain binding.

Mutation studies on the 40 bp genomic DNA fragment (EM4) that showed a shift was carried out by sequentially mutating 5 and 10 bases each along the sequence by transversion and carrying out EMSA on each mutant probe. For supershift experiments, 10 ug of $24 \mathrm{hpf}$ zebrafish nuclear extract was incubated with 10 nM EM4 probe and $1 \mathrm{ug}$ of antibody against the three predicted transcription factors (FOXA1: ab23738, PBX2: ab 66942, LEF1: ab 52017, all from Abcam plc), incubated for 1 hour and run on a gel as described above.

\section{Morpholinos}

The following two morpholinos against foxa1 were injected into about 2001 to 2-cell embryos at a concentration of 0.6-1.2 pico molar: 5'-CGCCCAACATTATGGAGGAAATCC-3' (M1) and 5'-CTTCCATTTTCACT GCGCCCAACAT-3' (M2). The specificity of foxa1 morpholinos was confirmed by using a standard scrambled control morpholino (CMO) 5'CCTCTTACCTCAGTTACAATTTATA-3' (Gene Tools).

\section{Western Blot}

Western blot was carried out as previously described [34] with some modifications. 10 morphants and wild type $24 \mathrm{hpf}$ zebrafish was used to extract protein using the NE-PER nuclear and cytoplasmic extraction kit (Thermo Scientific, USA) and 25 ug of nuclear extract was loaded on the gel. Foxa1 antibody (ab23738, Abcam
Plc) was applied in 1:500 dilution, followed by anti mouse IgG at 1:2500 dilution.

\section{RT-PCR}

Total RNA was extracted from wild type and morphant 24. hpf zebrafish using TRIzol (Invitrogen, USA) as per manufacture's instruction. Reverse transcription was performed using Superscript III (Invitogen, USA) and oligo DT primers. PCR was performed on the cDNA using the primers 5'-AATCTCCATCCGTCTACATT-3' and 5'-CAGGCCGTTCATGGCGTAGG-3' for $o t x 1 b$ and 5'-CGGTGACATCAAGGAGCT-3' and 5'TCGTGGATACCGCAAGATTCC-3' for b-actin.

\section{Additional material}

\begin{abstract}
Additional file 1: Genomic Location of CNEs tested. Genomic
locations of all CNEs tested and details of PCR primers.

Additional file 2: Zebrafish transient transgenics. Numerical details of the transient transgenic experiments in zebrafish.

Additional file 3: Immunohistochemistry for EGFP driven by $n k x 3.2$ enhancer. (A) Enhancer Bx4 driven EGFP expresses in the sclerotomal cells (black arrow) at $24 \mathrm{hpf}$. As marked by $n k \times 3.2$ in the section RNA in situ hybridization (B)

Additional file 4: BAC modification process. (A) The UCSC genome browser showing two BACs (red arrows) spanning the gene $n k \times 3.2$ in zebrafish. (B) BAC modification by homologous recombination to insert a reporter gene and a drug selection cassette next to the translation start site of the gene (ATG). (C) A zebrafish carrying the modified BAC for the gene $n k \times 3.2$ expressing EGFP in sclerotomes (white arrows) at $24 \mathrm{hpf}$. Abbreviations: EGFP, enhanced green fluorescent protein; NEO, neomycin; LHA, left homology arm; RHA, right homology arm; TGA, stop codon.

Additional file 5: Immunohistochemistry for EGFP driven by pax9 enhancers. (A) Enhancer Px2 driven EGFP expresses in the sclerotomal cells (black arrow) at $36 \mathrm{hpf}$. The red arrow indicates background staining. Similar expression domains can be seen for enhancer Px4 (B) at 36 hpf and Px7 (C) at 48 hpf. (D) the negative control (empty vector injection) shows no staining in the sclerotome. (E) Section RNA in situ hybridization for pax9 at $36 \mathrm{hpf}$.
\end{abstract}

Additional file 6: Probe sequences used for EMSA and TRANSFAC details. Mutants probes used for EMSA and TRANSFAC score for putative transcription factors bound to the enhancer.

Additional file 7: Western Blot and RT_PCR in Foxa1 morphants. (A) Whole zebrafish nuclear extracts probed with Foxa1 antibody. Wild type (WT), Scrambled morpholino (CMO). Morpholino 1 (M1), Morpholino 2 (M2). LOWER PANEL: anti Histone $\mathrm{H} 3$ blot to show loading control. (B) RT-PCR on RNA extracted from 24 hpf zebrafish embryos. Lane A: WT, Lane B: M1, Lane C: M2. (All otx1b primers). Lane D-F. PCR on same samples using $b$-actin primers as internal control. M-100 bp ladder. (C) RNA in situ hybridization for otx 16 in WT and Foxa1 morphant embryos.

Acknowledgements and fundings

This work is supported by the Agency for Science, Technology and Research (Singapore).

\section{Author details}

${ }^{1}$ Stem Cell and Developmental Biology, Genome Institute of Singapore, 60 Biopolis Street, 138672, Singapore. 'Department of Biological Sciences, National University of Singapore, 117543 , Singapore. ${ }^{3}$ Computational and 
Mathematical Biology, Genome Institute of Singapore, 60 Biopolis Street, 138672, Singapore.

\section{Authors' contributions}

SC participated in the design of the study, carried out the experimentation, helped in the interpretation of the results and help to draft the manuscript. GB participated in the interpretation of the data. TL conceived of the study and participated in its design and coordination and helped to draft the manuscript. All authors read and approved the final manuscript.

Received: 31 August 2011 Accepted: 20 October 2011

Published: 20 October 2011

\section{References}

1. Goto T, Macdonald P, Maniatis T: Early and late periodic patterns of even skipped expression are controlled by distinct regulatory elements that respond to different spatial cues. Cell 1989, 57(3):413-422.

2. Frasch M, Levine M: Complementary patterns of even-skipped and fushi tarazu expression involve their differential regulation by a common set of segmentation genes in Drosophila. Genes Dev 1987, 1(9):981-995.

3. Davidson EH, Rast JP, Oliveri P, Ransick A, Calestani C, Yuh CH, Minokawa T, Amore G, Hinman V, Arenas-Mena C, et al: A genomic regulatory network for development. Science 2002, 295(5560):1669-1678.

4. Banerji J, Rusconi S, Schaffner W: Expression of a beta-globin gene is enhanced by remote SV40 DNA sequences. Cell 1981, 27 (2 Pt 1):299-308.

5. Blackwood EM, Kadonaga JT: Going the distance: a current view of enhancer action. Science 1998, 281(5373):60-63.

6. Khoury G, Gruss P: Enhancer elements. Cell 1983, 33(2):313-314.

7. Levine $M$, Tjian R: Transcription regulation and animal diversity. Nature 2003, 424(6945):147-151.

8. Bagheri-Fam S, Barrionuevo F, Dohrmann U, Gunther T, Schule R, Kemler R, Mallo M, Kanzler B, Scherer G: Long-range upstream and downstream enhancers control distinct subsets of the complex spatiotemporal Sox 9 expression pattern. Dev Biol 2006, 291(2):382-397.

9. Antonellis A, Huynh JL, Lee-Lin SQ, Vinton RM, Renaud G, Loftus SK, Elliot G, Wolfsberg TG, Green ED, McCallion AS, et al: Identification of neural crest and glial enhancers at the mouse Sox 10 locus through transgenesis in zebrafish. PLoS Genet 2008, 4(9):e1000174.

10. Keene MA, Corces V, Lowenhaupt $K$, Elgin SC: DNase I hypersensitive sites in Drosophila chromatin occur at the $5^{\prime}$ ends of regions of transcription. Proc Natl Acad Sci USA 1981, 78(1):143-146.

11. McGhee JD, Wood WI, Dolan M, Engel JD, Felsenfeld G: A 200 base pair region at the $5^{\prime}$ end of the chicken adult beta-globin gene is accessible to nuclease digestion. Cell 1981, 27(1 Pt 2):45-55.

12. Allende ML, Manzanares M, Tena JJ, Feijoo CG, Gomez-Skarmeta JL: Cracking the genome's second code: enhancer detection by combined phylogenetic footprinting and transgenic fish and frog embryos. Methods 2006, 39(3):212-219.

13. Fisher S, Grice EA, Vinton RM, Bessling SL, McCallion AS: Conservation of RET regulatory function from human to zebrafish without sequence similarity. Science 2006, 312(5771):276-279.

14. Pennacchio LA, Ahituv N, Moses AM, Prabhakar S, Nobrega MA, Shoukry M, Minovitsky S, Dubchak I, Holt A, Lewis KD, et al: In vivo enhancer analysis of human conserved non-coding sequences. Nature 2006, 444(7118):499-502.

15. Petrykowska HM, Vockley CM, Elnitski L: Detection and characterization of silencers and enhancer-blockers in the greater CFTR locus. Genome Res 2008, 18(8):1238-1246.

16. Cooper GM, Brudno M, Stone EA, Dubchak I, Batzoglou S, Sidow A: Characterization of evolutionary rates and constraints in three Mammalian genomes. Genome Res 2004, 14(4):539-548.

17. DeSilva U, Elnitski L, Idol JR, Doyle JL, Gan W, Thomas JW, Schwartz S, Dietrich NL, Beckstrom-Sternberg SM, McDowell JC, et al: Generation and comparative analysis of approximately $3.3 \mathrm{Mb}$ of mouse genomic sequence orthologous to the region of human chromosome $7 q 11.23$ implicated in Williams syndrome. Genome Res 2002, 12(1):3-15.

18. Sandelin A, Bailey P, Bruce S, Engstrom PG, Klos JM, Wasserman WW, Ericson J, Lenhard B: Arrays of ultraconserved non-coding regions span the loci of key developmental genes in vertebrate genomes. BMC Genomics 2004, 5(1):99.
19. Woolfe A, Goodson M, Goode DK, Snell P, McEwen GK, Vavouri T, Smith SF, North P, Callaway H, Kelly K, et al: Highly conserved non-coding sequences are associated with vertebrate development. PLOS Biol 2005, 3(1):e7.

20. McGaughey DM, Vinton RM, Huynh J, Al-Saif A, Beer MA, McCallion AS: Metrics of sequence constraint overlook regulatory sequences in an exhaustive analysis at phox2b. Genome Res 2008, 18(2):252-260.

21. Blow MJ, McCulley DJ, Li Z, Zhang T, Akiyama JA, Holt A, Plajzer-Frick I, Shoukry M, Wright C, Chen F, et al: ChIP-Seq identification of weakly conserved heart enhancers. Nat Genet 42(9):806-810.

22. Visel A, Blow MJ, Li Z, Zhang T, Akiyama JA, Holt A, Plajzer-Frick I, Shoukry M, Wright $C$, Chen F, et al: ChIP-seq accurately predicts tissuespecific activity of enhancers. Nature 2009, 457(7231):854-858.

23. Heintzman ND, Stuart RK, Hon G, Fu Y, Ching CW, Hawkins RD, Barrera LO, Van Calcar S, Qu C, Ching KA, et al: Distinct and predictive chromatin signatures of transcriptional promoters and enhancers in the human genome. Nat Genet 2007, 39(3):311-318.

24. Heintzman ND, Hon GC, Hawkins RD, Kheradpour P, Stark A, Harp LF, Ye Z, Lee LK, Stuart RK, Ching CW, et al: Histone modifications at human enhancers reflect global cell-type-specific gene expression. Nature 2009, 459(7243):108-112.

25. Martindale MQ, Pang K, Finnerty JR: Investigating the origins of triploblasty: 'mesodermal' gene expression in a diploblastic animal, the sea anemone Nematostella vectensis (phylum, Cnidaria; class, Anthozoa). Development 2004, 131(10):2463-2474.

26. Rodaway A, Patient R: Mesendoderm. an ancient germ layer? Cell 2001, 105(2):169-172.

27. Khandekar M, Suzuki N, Lewton J, Yamamoto M, Engel JD: Multiple, distant Gata2 enhancers specify temporally and tissue-specific patterning in the developing urogenital system. Mol Cell Biol 2004, 24(23):10263-10276.

28. Mortlock DP, Guenther C, Kingsley DM: A general approach for identifying distant regulatory elements applied to the Gdf6 gene. Genome Res 2003, 13(9):2069-2081

29. Tribioli C, Lufkin T: The murine Bapx1 homeobox gene plays a critical role in embryonic development of the axial skeleton and spleen. Development 1999, 126(24):5699-5711.

30. Lettice L, Hecksher-Sorensen J, Hill R: The role of Bapx1 (Nkx3.2) in the development and evolution of the axial skeleton. J Anat 2001, 199(Pt 12):181-187.

31. Miller CT, Yelon D, Stainier DY, Kimmel CB: Two endothelin 1 effectors, hand2 and bapx1, pattern ventral pharyngeal cartilage and the jaw joint. Development 2003, 130(7):1353-1365.

32. Wilson J, Tucker AS: Fgf and Bmp signals repress the expression of Bapx1 in the mandibular mesenchyme and control the position of the developing jaw joint. Dev Biol 2004, 266(1):138-150.

33. Crotwell PL, Mabee PM: Gene expression patterns underlying proximaldistal skeletal segmentation in late-stage zebrafish, Danio rerio. Dev Dyn 2007, 236(11):3111-3128.

34. Chatterjee S, Min L, Karuturi RK, Lufkin T: The role of post-transcriptional RNA processing and plasmid vector sequences on transient transgene expression in zebrafish. Transgenic Res 19(2):299-304.

35. Mise T, lijima M, Inohaya K, Kudo A, Wada H: Function of Pax1 and Pax9 in the sclerotome of medaka fish. Genesis 2008, 46(4):185-192.

36. Hammond $\mathrm{KL}$, Whitfield $\Pi \mathrm{T}$ : The developing lamprey ear closely resembles the zebrafish otic vesicle: otx 1 expression can account for all major patterning differences. Development 2006, 133(7):1347-1357.

37. Foucher I, Mione M, Simeone A, Acampora D, Bally-Cuif L, Houart C Differentiation of cerebellar cell identities in absence of Fgf signalling in zebrafish Otx morphants. Development 2006, 133(10):1891-1900.

38. Sasaki H, Hogan BL: Differential expression of multiple fork head related genes during gastrulation and axial pattern formation in the mouse embryo. Development 1993, 118(1):47-59.

39. Ang SL, Wierda A, Wong D, Stevens KA, Cascio S, Rossant J, Zaret KS: The formation and maintenance of the definitive endoderm lineage in the mouse: involvement of HNF3/forkhead proteins. Development 1993, 119(4):1301-1315.

40. Monaghan AP, Kaestner KH, Grau E, Schutz G: Postimplantation expression patterns indicate a role for the mouse forkhead/HNF-3 alpha, beta and gamma genes in determination of the definitive endoderm, chordamesoderm and neuroectoderm. Development 1993, 119(3):567-578. 
41. Norton WH, Mangoli M, Lele Z, Pogoda HM, Diamond B, Mercurio S, Russell C, Teraoka H, Stickney HL, Rauch GJ, et al: Monorail/Foxa2 regulates floorplate differentiation and specification of oligodendrocytes, serotonergic raphe neurones and cranial motoneurones. Development 2005, 132(4):645-658.

42. Wingender $E$, Dietze $P$, Karas $H$, Knuppel R: TRANSFAC: a database on transcription factors and their DNA binding sites. Nucleic Acids Res 1996, 24(1):238-241.

43. Hare EE, Peterson BK, Iyer VN, Meier R, Eisen MB: Sepsid even-skipped enhancers are functionally conserved in Drosophila despite lack of sequence conservation. PLoS Genet 2008, 4(6):e1000106.

44. Li Q, Ritter D, Yang N, Dong Z, Li H, Chuang JH, Guo S: A systematic approach to identify functional motifs within vertebrate developmental enhancers. Dev Bio/ 337(2):484-495.

45. Gong S, Zheng C, Doughty ML, Losos K, Didkovsky N, Schambra UB, Nowak NJ, Joyner A, Leblanc G, Hatten ME, et al: A gene expression atlas of the central nervous system based on bacterial artificial chromosomes. Nature 2003, 425(6961):917-925.

46. Sato Y, Miyasaka N, Yoshihara Y: Hierarchical regulation of odorant receptor gene choice and subsequent axonal projection of olfactory sensory neurons in zebrafish. J Neurosci 2007, 27(7):1606-1615.

47. Jessen JR, Meng A, McFarlane RJ, Paw BH, Zon LI, Smith GR, Lin S: Modification of bacterial artificial chromosomes through chi-stimulated homologous recombination and its application in zebrafish transgenesis. Proc Natl Acad Sci USA 1998, 95(9):5121-5126.

48. Yang Z, Jiang $H$, Chachainasakul T, Gong S, Yang XW, Heintz N, Lin S: Modified bacterial artificial chromosomes for zebrafish transgenesis. Methods 2006, 39(3):183-188.

49. Long $Q$, Meng A, Wang H, Jessen JR, Farrell MJ, Lin S: GATA-1 expression pattern can be recapitulated in living transgenic zebrafish using GFP reporter gene. Development 1997, 124(20):4105-4111.

50. Xie X, Lu J, Kulbokas EJ, Golub TR, Mootha V, Lindblad-Toh K, Lander ES, Kellis M: Systematic discovery of regulatory motifs in human promoters and 3' UTRs by comparison of several mammals. Nature 2005, 434(7031):338-345

51. Bejerano G, Pheasant M, Makunin I, Stephen S, Kent WJ, Mattick JS, Haussler D: Ultraconserved elements in the human genome. Science 2004, 304(5675):1321-1325.

52. Glazko GV, Koonin EV, Rogozin IB, Shabalina SA: A significant fraction of conserved noncoding DNA in human and mouse consists of predicted matrix attachment regions. Trends Genet 2003, 19(3):119-124.

53. Glazov EA, Pheasant M, Nahkuri S, Mattick JS: Evidence for control of splicing by alternative RNA secondary structures in Dipteran homothorax pre-mRNA. RNA Biol 2006, 3(1):36-39.

54. Bejerano G, Lowe CB, Ahituv N, King B, Siepel A, Salama SR, Rubin EM, Kent WJ, Haussler D: A distal enhancer and an ultraconserved exon are derived from a novel retroposon. Nature 2006, 441(7089):87-90.

55. Qiu X, Xu H, Haddon C, Lewis J, Jiang YJ: Sequence and embryonic expression of three zebrafish fringe genes: lunatic fringe, radical fringe, and manic fringe. Dev Dyn 2004, 231(3):621-630.

56. Kimmel CB, Ballard WW, Kimmel SR, Ullmann B, Schilling TF: Stages of embryonic development of the zebrafish. Dev Dyn 1995, 203(3):253-310.

57. Muller F, Williams DW, Kobolak J, Gauvry L, Goldspink G, Orban L, Maclean N: Activator effect of coinjected enhancers on the musclespecific expression of promoters in zebrafish embryos. Mol Reprod Dev 1997, 47(4):404-412

58. Goode DK, Callaway HA, Cerda GA, Lewis KE, Elgar G: Minor change, major difference: divergent functions of highly conserved cis-regulatory elements subsequent to whole genome duplication events. Development 138(5):879-884.

59. Chatterjee S, Lufkin T: Fishing for function: zebrafish BAC transgenics for functional genomics. Mol Biosyst 2011, 7(8):2345-2351.

doi:10.1186/1471-213X-11-63

Cite this article as: Chatterjee et al: Conserved and non-conserved enhancers direct tissue specific transcription in ancient germ layer specific developmental control genes. BMC Developmental Biology 2011 11:63.

\section{Submit your next manuscript to BioMed Central and take full advantage of:}

- Convenient online submission

- Thorough peer review

- No space constraints or color figure charges

- Immediate publication on acceptance

- Inclusion in PubMed, CAS, Scopus and Google Scholar

- Research which is freely available for redistribution 